\title{
Resiliência e impactos regionais de crises financeiras: uma análise para os estados brasileiros - 2007/08 *
}

\author{
Igor Santos Tupy ** \\ Marco Crocco \\ Fernanda Faria Silva
}

\begin{abstract}
Resumo
Este artigo analisa os impactos diferenciados da crise financeira global de 2007/2008 sobre os estados brasileiros. Examinaram-se os padrões diferenciados de resistência e recuperação da atividade econômica a partir do emprego formal e da produção industrial com a construção de dois indicadores Índice de Sensibilidade e Índice de Recuperação - e a estimação de uma "Equação de Resiliência" utilizando o modelo SUR (Regressões Aparentemente Não-Relacionadas). Os resultados evidenciam a heterogeneidade nos impactos do choque recessivo comum sobre os estados brasileiros, que ocorreram em termos de amplitude, timming, duração dos efeitos sobre a atividade econômica, bem como de resistência e recuperação.
\end{abstract}

Palavras-chave: Crise financeira; Economia regional; Impactos diferenciados de política monetária; Resiliência regional; Economia brasileira.

\section{Abstract \\ Regional resilience to and impacts of financial crises: an analysis of the Brazilian states - 2007/08.}

This paper aims to analyze the regional effects of the 2008 financial crisis' on Brazil's twenty-seven states and the different patterns of responses to this shock. The uneven patterns of resistance to and recovery from the recession were analyzed using two indicators - The Sensitivity Index and The Recovery Index - and a "Resilience Equation" estimated by Seemingly Unrelated Regressions (SUR Model). It was verified that a common recessive shock, in the financial crisis period, causes heterogeneous impacts on the Brazilian States. Such differences occurred in extent, timing and in the regional resistance and recovery to the shock.

Keywords: Financial crisis; Regional economics; Uneven impacts of monetary policy; Regional resilience.

JEL E52, R11, R51, R58.

\section{Introdução}

Desde a década de 1990 a economia brasileira tem sofrido as consequências de uma série de crises financeiras com dimensões globais, dentre as quais destacam-

*Artigo recebido em 23 de maio de 2016 e aprovado em 4 de abril de 2017.

** Doutorando em Economia no Centro de Desenvolvimento e Planejamento Regional (Cedeplar) / Faculdade de Ciências Econômicas da Universidade Federal de Minas Gerais (UFMG), Belo Horizonte, MG, Brasil. E-mail: igortupy@cedeplar.ufmg.br.

*** Professor titular do Cedeplar / Faculdade de Ciências Econômicas da UFMG e Presidente do Banco de Desenvolvimento de Minas Gerais (BDMG), Belo Horizonte, MG, Brasil. E-mail: crocco@ cedeplar.ufmg.br.

${ }^{* * * * *}$ Professora Adjunta do Departamento de Economia / Programa de Pós-Graduação em Economia Aplicada da Universidade Federal de Ouro Preto (UFOP), Ouro Preto, MG, Brasil. E-mail: ferfaria@ ufop.edu.br. 
se as crises do México (1995), Asiática (1997), Russa (1998), Argentina (2002) e a última delas, pós-2007 (Krugman, 2009). Entretanto, a crise econômica mais recente apresenta características que a difere das recessões anteriores em relação à sua profundidade e duração prolongada, sua amplitude e sua influência, bem como suas implicações estruturais para o sistema financeiro e para o investimento (Bailey; Berkeley, 2014).

A crise de 2008 teve origem no sistema imobiliário norte-americano a partir das hipotecas denominadas subprime. A concessão de empréstimos hipotecários aos agentes que não tinham condições de fornecer garantias aos bancos gerou uma forte expansão do mercado imobiliário. Mais adiante, essas hipotecas de alto risco foram reunidas em grande número de títulos financeiros sob os quais não se tinha informações sobre o risco. Sob esses títulos criaram-se ainda outros derivativos, bem classificados pelas agências de rating. Com a reversão das expectativas, sobretudo em 2007, e com a queda brusca no valor dos imóveis nos Estados Unidos foi que transpareceu a real dimensão da estrutura financeira frágil e complexa que se havia criado. A crise que se sucedeu ao estouro da dívida atingiu fortemente o mercado financeiro e, por ele, se espalhou rapidamente, tendo em vista o pânico instalado entre os agentes.

Os impactos diferenciados da última crise financeira global puderam ser observados por distintas formas e intensidades de transmissão de seus efeitos entre os países. No entanto, diferente dos padrões anteriores, os países desenvolvidos foram atingidos com maior intensidade e afetados mais rapidamente, enquanto o contágio em países periféricos se deu de forma menos intensa e mais lenta. Isso não quer dizer que esses países ficaram imunes e que os efeitos da crise do subprime não tenham se propagado internamente, de forma também diferenciada.

Nesse sentido, é importante destacar que a crise financeira global apresenta elementos espaciais bem definidos e, na maioria das vezes, ignorados nas análises econômicas. A espacialidade que envolve este e outros choques de natureza semelhante se configura não só no espalhamento de seus efeitos, mas também se mostra presente na gestação da crise, que não se criou num espaço abstrato do mercado financeiro (Wójcik, 2013). Em particular, as características espaciais do processo que levou à crise do subprime são fundamentais no entendimento dos padrões desiguais de disseminação dessa crise entre as diferentes regiões.

Blazek e Netrdová (2012) apontam que os fatores com relevância para a explicação dos impactos regionais de crises são muito diversos, incluindo a situação macroeconômica inicial, a estrutura territorial e os padrões econômicos de cada região. Apontam, ainda, que as variadas respostas nacionais também foram importantes fatores que contribuíram para a diversidade dos impactos da crise. 
O objetivo deste trabalho é investigar de que forma ocorreu a transmissão regional dos efeitos da recente crise financeira global sobre a economia brasileira. Especificamente, busca-se avaliar se os estados brasileiros responderam de maneira desigual aos efeitos da crise, examinando os padrões de respostas das unidades da federação por meio de uma análise da capacidade de resistência e recuperação do emprego. Para esta discussão, serão estudados os elementos teóricos relacionados ao conceito de Resiliência Regional - que consiste na capacidade que as regiões apresentam de lidar e reagir a choques, rupturas e mudanças rápidas que ocorrem num âmbito nacional ou mesmo global.

Períodos de crise nos ciclos econômicos e políticos, de acordo com Bristow (2010), têm servido como poderosos gatilhos para novas pesquisas e novos discursos. As recessões, em particular, pontos de inflexão nas trajetórias de desenvolvimento de curto e de longo-prazo, criam imperativos para mudanças nos hábitos, rotinas, convenções e políticas, não só para mitigar seus efeitos, mas também para a preparação para crises futuras. Portanto, a compreensão dos padrões regionais diferenciados dos impactos das crises pode permitir um aperfeiçoamento na implementação das políticas anticíclicas por parte do governo, podendo aliar ou reforçar - à política macroeconômica - um caráter regional que busque, além de mitigar os efeitos danosos das crises (no âmbito global), mitigar os impactos naquelas regiões mais vulneráveis, evitando um eventual aprofundamento das disparidades regionais.

Este estudo busca somar esforços, tal como propõem Bailey e Propris (2014), a uma corrente de trabalhos que tem analisado os efeitos da crise financeira global e da consequente restrição do crédito sobre as regiões e sub-regiões em todo o mundo, mas que ainda não parece consolidada no Brasil. Nesse aspecto, traz-se a discussão dos efeitos da crise financeira para o âmbito dos estados brasileiros.

Como exercício empírico, este artigo pretende analisar alguns aspectos relacionados à resiliência econômica dos estados brasileiros, seguindo metodologia proposta por Fingleton et al. (2012) e Cellini e Torrisi (2014). Esta metodologia compreende a construção de dois indicadores que permitem uma análise exploratória das respostas regionais ao choque recessivo (Índice de Sensibilidade e Índice de Recuperação) e a estimação de um modelo que busca captar efeitos específicos dos choques sobre o comportamento do emprego nos estados, através do Modelo de Regressões Aparentemente Não-Relacionadas (Seemingly Unrelated Regressions SUR).

Este artigo está estruturado em 5 seções, incluindo esta introdução. $\mathrm{Na}$ primeira seção será apresentado o arcabouço teórico que trata dos impactos das crises financeiras sob a perspectiva regional, incluindo a temática da resiliência regional. Na segunda parte, é apresentado e justifica-se o esforço empírico realizado no artigo. 
Na terceira, são analisados os resultados do impacto regional da crise financeira de 2007-2008, incluindo a sua capacidade de resiliência regional. Por fim, seguem-se as considerações finais e apresentação das referências bibliográficas.

\section{0 resgate da questão regional na análise dos impactos das crises}

Muito tem-se discutido na teoria econômica, sob vários matizes teóricos, os impactos das crises de todas as naturezas sobre o sistema econômico em nível de países. Tais discussões tem refletido sobre as políticas anticíclicas possíveis para mitigação de tais efeitos sobre o nível de renda e produção da nação. Como afirmam Fingleton et al. (2012), existem evidências de que choques recessivos severos tendem a deprimir as taxas de crescimento de longo prazo dos países. Entretanto, tais impactos não ocorrem uniformemente em todo o território de um mesmo país, afetando as regiões de forma diferenciada. Dessa forma, os padrões gerais apresentados por um choque recessivo na economia nacional podem mascarar importantes agravamentos nas disparidades regionais.

Fingleton et al. (2012), sugerem ainda que poucos estudos aprofundaram-se na análise da forma como o crescimento regional varia ao longo do tempo; quando e porque essas variações diferem de região para região. Menos ainda, de acordo com eles, são os estudos que abordam os impactos dos grandes choques recessivos sobre os padrões de crescimento regional de longo prazo. Francis et al. (2012), contudo, afirmam que a literatura sobre as assimetrias regionais nos ciclos de negócios, a incidência de choques regionais e as respostas diferenciadas aos choques agregados é crescente.

Como afirmam Bailey e Berkeley (2014), o período de queda na atividade econômica acelerou alguns processos chave de mudanças estruturais que já estavam em curso, como o declínio do emprego no setor manufatureiro em regiões industriais maduras. A Crise Financeira Global também evidenciou a importância das respostas em termos de política econômica por parte das mais variadas esferas de governos, sendo apontadas como determinantes dos efeitos diferenciados deste choque, sobre países e economias locais. Para Bailey e Berkeley (2014), a incerteza a respeito dos impactos espaciais da recessão e da crise de crédito requer uma liderança em diferentes escalas: nacionais, regionais e locais. Questionando sobre tais impactos, os policy-markers podem, de acordo com Lee (2014), buscar um direcionamento de recursos para aquelas cidades economicamente mais frágeis de modo a tornarem suas cidades mais resilientes às futuras crises econômicas. É nesse contexto de construção teórica que este trabalho se insere, trazendo esta discussão para a configuração regional brasileira, avaliando as características dos impactos regionalmente diferenciados. 
Portanto, o cerne da discussão deste artigo está nas possíveis implicações desta crise, na qual os choques de mesma natureza incidem de forma distinta sobre o lado real da economia. Mais ainda, o que este trabalho busca é captar essas formas de transmissão sobre as economias regionais, as restrições que se impõem sobre elas e suas peculiaridades e características que amenizam ou potencializam tais efeitos globais. Nesse aspecto, a forma como as regiões respondem aos choques recessivos, afirmam Fingleton et al. (2012), aparece como uma questão pertinente a ser discutida a respeito dos padrões de crescimento regional de longo prazo e, portanto, quando as rendas regionais e outras dimensões das disparidades regionais convergem ou divergem ao longo do tempo.

Dessa forma, de acordo com Lee (2014), as recessões apresentam impactos espaciais particulares, que refletem tanto a natureza das mudanças na economia nacional quanto as características individuais das economias locais. Na visão de Cellini e Torrisi (2014), por sua vez, o choque afeta a economia regional através de seus impactos imediatos (heterogêneos ou homogêneos) e da capacidade de recuperação, pela qual altera a performance permanente no longo prazo.

Para Lee (2014), são essencialmente três os canais que determinam os impactos da recessão sobre as economias regionais, em processos que operam a forma da elevação no desemprego a nível local. O primeiro deles seriam os efeitos específicos da recessão, relacionados com a natureza peculiar da crise e de como o choque de demanda é sentido (no caso deste artigo, trata-se da crise financeira e o colapso no mercado imobiliário). Em segundo lugar, tem-se os efeitos gerais devidos à redução na demanda na economia, impactando sobre setores em particular. Por fim, os efeitos multiplicadores nas economias locais à medida que o aumento no desemprego reduz a demanda local.

Mesmo considerando-se a divisão dos efeitos como proposto por Lee (2014), concebe-se que os desdobramentos desiguais da crise sobre as regiões ocorrem não só nos efeitos multiplicadores, mas também nos efeitos específicos, a partir da conformação das economias locais. Isto é, considera-se também como o sistema econômico da região está relacionado ao mercado financeiro nacional e internacional e, ainda, os efeitos gerais, a depender da estrutura produtiva da região e de como os setores de atividade econômica predominantes a nível local dependem e relacionamse com o comércio externo e com o setor financeiro, por exemplo.

Blazek e Netrdová (2012) apontam a existência de uma diversidade nas tendências gerais em relação aos impactos da crise a partir da combinação de vários fatores para os estados europeus, com uma tendência de maior intensidade na dimensão regional. De acordo com os autores, o primeiro grupo consiste nos fatores hard que se constituem de elementos primariamente macroeconômicos e geográficos. O segundo agrupamento é de fatores soft, incluindo elementos 
institucionais e subjetivos. Assim, os fatores e mecanismos são, como mostram eles, muito diversos e incluem características desde a situação macroeconômica espacial até a estrutura territorial dos padrões econômicos. De todo modo, os autores indicam uma série de elementos para explicar os efeitos diferenciados da crise financeira entre unidades espaciais:

i) os impactos espaciais do capital estrangeiro, beneficiando regiões metropolitanas;

ii) impactos espaciais do comércio, favorecendo regiões com estrutura produtiva diversificada;

iii) abertura e integração econômica;

iv) mudanças estruturais e seus impactos espaciais;

v) baixos custos de transação nas estruturas econômicas diversificadas;

vi) elementos financeiros regionais tais como o volume de empréstimos baratos no período pré-crise, empréstimos em moeda estrangeira, estrutura da propriedade bancária;

vii) estratégias de competitividade de firmas e setores chave e suas posições na cadeia global de valor; e

viii) fatores político-institucionais - qualidade da administração pública, amplitude regional das políticas públicas, tamanho e descentralização do setor público.

Em outro estudo, Davies (2011), ressaltara a importância da habilidade das autoridades políticas em garantirem um planejamento efetivo e estratégias de implementação como respostas aos choques. Segundo ela, a dimensão política é particularmente importante na recente crise, não apenas em função do choque financeiro ter tido a participação do governo ou porque os governos também tiveram papel importante na mitigação dos efeitos da crise, mas também porque a crise está levando a cortes de gastos públicos que tendem a ter efeitos mais fortes em regiões estruturalmente mais fracas que possuem, normalmente, níveis de emprego no setor público e em empresas que ofertam para o setor público acima da média, bem como de maiores parcelas das suas populações que dependem dos serviços públicos e de medidas públicas de promoção do bem-estar social.

Outro ponto destacado por Blazek e Netrdová (2012) é que o relacionamento entre uma recessão econômica e a escala das disparidades regionais depende da amplitude e da natureza da crise. Nesse sentido, Hulka (2007, apud Blazek e Netrdová, 2012) indica que aumentos das desigualdades regionais durante um período de recessão econômica se devem, sobretudo, a que: i. Regiões periféricas são, em geral, especializadas em setores mais sensíveis a crises econômicas; ii. 
Firmas das regiões mais desenvolvidas são mais flexíveis e mais bem equipadas em termos de tecnologia, utilizando vantagens de aglomeração e acessando maiores reservas financeiras de forma a reduzir as chances de falência; e iii. Menor volume de recursos para políticas públicas redistributivas durante períodos de recessão. Alguns outros elementos são apontados nos dois tópicos seguintes que destacam o papel da preferência pela liquidez diferenciada no espaço e o papel da resiliência regional.

A discussão apresentada permite reforçar que as economias regionais vão reagir de formas diversas aos choques monetários, o que pode exercer influências sobre os padrões de disparidades regionais e de desenvolvimento regional desigual dentro de um país.

\section{$1.1 O$ conceito de resiliência econômica regional}

O conceito de Regional Resilience busca capturar as habilidades desiguais e diferenciadas das regiões para reagir, responder e lidar com a incerteza, volatilidade e mudanças rápidas (Pike et al., 2010) que ocorrem em decorrência de choques. E como completam Simmie e Martin (2010), a noção de resiliência parece ser altamente relevante no entendimento de padrões e processos do desenvolvimento regional desigual, tendo como motivação empírica o fato de os desenvolvimentos econômicos local e regional não configurarem um processo suave, estando sujeitos a todo tipo de interrupções e rupturas.

Christopherson et al. (2010), por sua vez, acreditam que a atenção dada à resiliência recentemente possa ser uma resposta ao senso contemporâneo de incerteza e insegurança generalizada e à busca por fórmulas de adaptação e sobrevivência, em que o aumento do seu uso se origine, além de tal senso de risco econômico, político e ambiental - crescente, da percepção de que processos associados à globalização têm feito localidades e regiões mais "permeáveis" aos efeitos de eventos que ocorrem fora de seus territórios. Por sua vez, segundo Pike et al. (2010), as discussões em desenvolvimento regional têm se aproximado da resiliência regional em resposta a tais choques externos e transições cada vez mais diversas que incluem as crises financeiras, drásticas mudanças e eventos climáticos, atos terroristas.

Mais especificamente, Bristow (2010) ressalta que a recente crise global e a consequente elevação da insegurança têm destacado as vantagens daquelas economias locais e regionais que possuem maior resiliência, em virtude de uma menor dependência de atividades globais, maior diversidade econômica ou determinação de priorizar e realizar mudanças estruturais mais significantes. Ela reforça que esse período deu ênfase à vulnerabilidade de muitas economias regionais aos distúrbios internacionais, bem como às diferenças nas capacidades das regiões para se adaptarem diante de tais pressões, com variações no tempo e nos canais de 
impacto, a depender de elementos como grau de abertura a instrumentos financeiros internacionais sofisticados, presença ou não de bolhas imobiliárias e a importância de manufaturados na economia regional. Portanto, este aumento na percepção de vulnerabilidade tem estimulado a busca de novos caminhos para a "resiliência" (Cristopherson et al., 2010) e voltado as atenções para a capacidade dos governos em mitigar os impactos dos choques internacionais, bem como os efeitos regionalmente diferenciados da intervenção governamental (Davies, 2011).

Para Christopherson et al. (2010), uma das razões para a popularidade do termo regional resilience tem sido a sua maleabilidade, podendo significar diferentes coisas para pessoas diferentes. O termo resiliência é utilizado em várias áreas do conhecimento, como destacam Pike et al. (2010), por exemplo, psicologia e psiquiatria, sistemas ecológicos, engenharia, ciências sociais e ciências econômicas. Segundo eles, essas concepções através das disciplinas dão à resiliência significados diferentes e particulares. De fato, como Simmie e Martin (2010) destacam, não há uma definição de resiliência aceita universalmente em economia ou ciência social. Simmie e Martin (2010) e Pike et al. (2010) identificam quatro interpretações diferentes sobre a resiliência econômica regional: abordagem de equilíbrio único (engineering resilience), múltiplos equilíbrios, resiliência ecológica e resiliência na perspectiva evolucionária. O quadro a seguir sintetiza as principais formas de entendimento sobre a resiliência regional encontradas na literatura.

Quadro 1

Principais tipos e definições de resiliência

\begin{tabular}{|c|c|c|}
\hline Definição/tipo & Interpretação & Principais campos de uso \\
\hline $\begin{array}{l}\text { Resiliência como } \\
\text { "retornar" o } \\
\text { estado anterior ao } \\
\text { choque }\end{array}$ & $\begin{array}{c}\text { O Sistema Retorna ao estado ou } \\
\text { trajetória pré-choque: enfatiza a } \\
\text { velocidade e o grau de recuperação. }\end{array}$ & $\begin{array}{l}\text { Chamada "engineering resilience", } \\
\text { encontrada nas ciências exatas, } \\
\text { física, algumas abordagens da } \\
\text { ecologia e se aproxima da ideia de } \\
\text { auto-ajustamento e retorno ao } \\
\text { equilíbrio da economia mainstream. }\end{array}$ \\
\hline $\begin{array}{l}\text { Resiliência como } \\
\text { "capacidade de } \\
\text { absorver" } \\
\text { choques }\end{array}$ & $\begin{array}{l}\text { Enfatiza a estabilidade da estrutura } \\
\text { do sistema, sua função e identidade } \\
\text { em face aos choques. O tamanho do } \\
\text { choque que pode ser tolerado antes } \\
\text { de o sistema se mover para um } \\
\text { novo estado ou tomar nova forma. }\end{array}$ & $\begin{array}{l}\text { Conhecida como "resiliência } \\
\text { ecológica estendida" encontrada em } \\
\text { ecologia e ecologia social. } \\
\text { Aproxima-se da economia de } \\
\text { múltiplos equilíbrios. }\end{array}$ \\
\hline $\begin{array}{l}\text { Resiliência como } \\
\text { "adaptabilidade } \\
\text { positiva" em } \\
\text { antecipação ou } \\
\text { em resposta aos } \\
\text { choques. }\end{array}$ & $\begin{array}{l}\text { Capacidade do sistema manter as } \\
\text { principais performances apesar dos } \\
\text { choques adaptando suas estruturas, } \\
\text { funções e organização. Ideia de } \\
\text { "saltar para frente". }\end{array}$ & $\begin{array}{l}\text { Encontrada na psicologia e teorias } \\
\text { organizacionais. Aproxima-se da } \\
\text { robustez na teoria dos sistemas } \\
\text { complexos. Liga-se com a economia } \\
\text { evolucionária. }\end{array}$ \\
\hline
\end{tabular}

Fonte: Martin e Sunley (2015). 
Segundo Simmie e Martin (2010), a mais tradicional dessas definições, "engineering resilience", diz respeito à estabilidade do sistema em torno de um estado estacionário em que a velocidade de retorno a um equilíbrio pré-existente define a ideia de resiliência. Para os autores, esta abordagem está relacionada à noção de equilíbrio da teoria econômica mainstream e implica que uma região resiliente é aquela que retoma sua estrutura pré-choque.

De acordo com Pike et al. (2010), nesta abordagem baseada na existência de equilíbrio único, a resiliência é entendida como o grau ou contexto em que uma unidade espacial pode retornar para sua posição e nível pré-choque de emprego ou produto. Os autores afirmam que os pressupostos desta versão são limitados, pois consideram que o ajustamento do sistema se dá através da livre mobilidade dos fatores de mercado e subsequente retorno a um único estado de equilíbrio. Simmie e Martin (2010) destacam que pressupõe-se que o choque tira a economia de sua trajetória de equilíbrio mas forças auto corretoras e ajustamentos eventuais restaurariam a economia. Com essa definição, segundo os autores, torna-se difícil conciliar a ideia de resiliência com evolução econômica regional.

Por outro lado, afirmam Pike et al. (2010), outras concepções de resiliência têm sido elaboradas a partir de uma leitura institucionalista das ideias evolucionárias, incorporando a noção de dependência de trajetória em sistemas fechados e estruturas estáveis ao longo do tempo. Essas concepções são limitadas, segundo os autores, pela visão de ajustamentos em equilíbrios múltiplos. Nesse ínterim, de acordo com Simmie e Martin (2010), assume-se a ideia de que não há um único estado de equilíbrio, ou trajetória, mas muitos estados ou trajetórias possíveis. Sendo assim, um choque pode deslocar a economia para um outro ponto de equilíbrio, mas a economia não-resiliente estaria sujeita a um "lock-in", presa em uma estrutura obsoleta. A chamada "Resiliência Ecológica", segundo Simmie e Martin (2010), tem foco na capacidade dos choques e distúrbios causarem uma mudança do sistema a um outro regime de comportamento. Dessa maneira, a resiliência está relacionada à magnitude do choque, que pode ser absorvida antes mesmo do sistema mudar sua configuração após o choque.

Simmie e Martin (2010) ainda definem uma quarta tipologia para o estudo da resiliência regional: feito sob pressupostos evolucionários. Segundo eles, a economia nunca está em equilíbrio e a evolução desse sistema depende da ação de agentes econômicos individuais que podem aprender, inovar e ajustar seus comportamentos. Os autores afirmam que certamente as economias regionais apresentam uma estabilidade e uma auto-organização, mas estes conceitos não implicam na existência de um equilíbrio. Dessa maneira, de uma perspectiva evolucionária, o atributo principal da resiliência regional é a capacidade adaptativa das economias locais (Simmie; Martin, 2010). 
Para estes autores, a capacidade adaptativa de uma região consiste na sua habilidade diferencial (da região ou das firmas locais) de se adaptarem aos choques e às mudanças em competição, mercado, tecnologias, políticas e condições relacionadas que moldam a dinâmica evolucionária e trajetórias da economia local e regional ao longo do tempo. A adaptabilidade, segundo eles, diz respeito ao potencial de ajustamento a circunstâncias em transformação de uma maneira apropriada. Três mecanismos podem fazer com que firmas locais tornem-se mais bem adaptadas: a resposta intencional à percepção das circunstâncias, o seguimento automático de regras específicas com relação a comportamentos padrões e desdobramentos cumulativos de novos padrões de comportamento (como as inovações) dentro de um conjunto específico de restrições.

Portanto, sob a ótica evolucionária, os conceitos de adaptação e adaptabilidade emergem como elementos centrais para a construção da resiliência regional. Na concepção de Pike et al. (2010), adaptação é um movimento em torno de trajetórias pré-concebidas no curto prazo, caracterizado por fortes e estreitas ligações entre agentes sociais e lugares. Por outro lado, adaptabilidade consiste na capacidade dinâmica para executar e desdobrar múltiplas trajetórias pela perda ou enfraquecimento das ligações entre agentes sociais e os lugares, que melhoram a capacidade geral de resposta do sistema a mudanças inesperadas.

Como exemplo, Pike et al. (2010) afirmam que numa antiga região industrial, a adaptação pode explicar uma forma de resiliência baseada na renovação, no curto prazo, de uma trajetória de desenvolvimento pré-concebida e bem-sucedida anteriormente. A adaptabilidade, por outro lado, pode explicar um tipo diferente de resiliência que deve lidar com características imprevistas, emergindo de decisões de abandonar uma trajetória que tenha se provado bem sucedida no passado em favor de uma nova trajetória, relacionada ou alternativa, o que carrega uma série de desafios substantivos no desenvolvimento de capacidades e tolerância para lidar com incerteza, ineficiência econômica e impopularidade política de se mover de uma posição regional estabelecida, para uma alternativa. Pike et al. (2010) entendem que adaptação e adaptabilidade podem oferecer tanto explicações contrastantes para as resiliências diferenciadas dos lugares, quanto serem complementares para explicar como os diferentes elementos de uma região - setores, mercado de trabalho, interesses políticos - podem se integrar para gerar uma forma mais complexa de resiliência para qualquer lugar particular.

Ao se pensar em termos de adaptação e adaptabilidade dos agentes e os mecanismos para distinguir quantitativamente e qualitativamente sobre as dimensões da resiliência, chega-se a considerações de curto prazo, quanto a respostas reativas aos choques, e de longo prazo, envolvendo estratégias proativas (Pike et al., 2010). Para Pike et al. (2010), enquanto o curto prazo se confronta com aspectos quantitativos de desafios imediatos, a visão de longo prazo relaciona-se com 
questões qualitativas com a reflexão acerca das diferentes saídas através de trajetórias mais hábeis para resistir às recorrências dos choques. De acordo com Simmie e Martin (2010), tais respostas criativas e flexíveis aos choques vão depender da capacidade inovativa das firmas locais, das capacidades empreendedoras e formação de novas firmas, inovação institucional, acesso a investimento e venture capital, disposição dos trabalhadores de recapacitarem-se e de outros fatores similares.

Segundo Christopherson et al. (2010), os fatores que habilitam uma região a se ajustar e se adaptar ao longo do tempo são diversos e se diferenciam entre as regiões, mas podem-se encontrar com mais força alguns fatores que influenciam na resiliência das regiões, como um sistema regional de inovação robusto, fatores que gerem maior aprendizado na região, uma moderna infraestrutura produtiva que envolva, por exemplo, rede eficiente de transportes e comunicação, uma força de trabalho habilidosa, inovativa e empreendedora, um sistema financeiro desenvolvido para fornecimento de capital de longo prazo e uma base econômica diversificada, que não dependa demasiadamente de uma única indústria.

A tradicional questão que confronta especialização versus diversificação permanece, segundo Pike et al. (2010), influenciando as discussões acerca de que tipo de economias locais e regionais são mais propensas a adaptação e a mostrarem adaptabilidade. Nesse sentido, Simmie e Martin (2010) relatam que o grau de diversidade de setores locais é tido como fator que influencia a vulnerabilidade da economia regional a choques exógenos. Segundo eles, regiões com estrutura econômica mais diversificada são menos propensas a choques, ou pelo menos mais preparadas para se recuperar deles. Por sua vez, afirmam que as regiões economicamente mais especializadas são não só propensas a choques num setor específico, mas também não possuem amplitude de atividades econômicas capazes de compensar tais distúrbios adversos. Além disso, indicam que variedade produtiva também influencia a atividade inovativa de firmas locais, mas havendo uma discussão sobre quando uma estrutura diversificada é mais propícia à inovação do que uma estrutura especializada.

Pike et al. (2010) destacam, também, que elementos políticos são amplamente negligenciados dos trabalhos existentes sobre resiliência, mas que o entendimento de como a adaptação e a adaptabilidade afetam a resiliência regional requer a compreensão de como as relações de poder, política e cooperação diferenciadas entre capital, trabalho, Estado e sociedade civil se delineiam e são moldados pelas trajetórias evolucionárias. Assim, ao buscar entender os fatores que afetam a capacidade das economias regionais responderem às mudanças e recuperarem-se de choques significantes que se originam de fora da região, é inevitável, na visão de Christopherson et al. (2010), cair em questões sobre os fatores 
como a formulação de política e estrutura de governança apropriada que podem habilitar, acomodar e facilitar mudanças.

Percebe-se, portanto, que o conceito de Resiliência Regional apresenta potencial de discussão sobre o desenvolvimento regional em face às crises e rupturas que atingem os sistemas econômicos regionais constantemente. Entretanto, o conceito está envolto em consideráveis nuances e pontos de vista que distinguem, sobremaneira, as formas de abordá-lo.

\section{Metodologia}

Para analisar o comportamento dos estados brasileiros em termos de resistência e recuperação do emprego após a crise, adota-se como referência os artigos recentes de Fingleton et al. (2012), Cellini e Torrisi (2014), Di Caro et al. (2014) e Eraydin (2016) ${ }^{1}$. Tais referências fornecem um instrumental simples e útil para uma primeira análise empírica da resiliência nas regiões brasileiras à crise financeira global, pois permite que se explorem, sobretudo, as diferenças entre os estados (ou unidades espaciais que sejam) em termos de resistência - ou sensibilidade - e recuperação dos choques, analisando essencialmente o comportamento das séries de dados utilizados como proxies para a dinâmica da atividade econômica. Contudo, é importante ressaltar que esta metodologia ainda não consegue incorporar todas as dimensões e aspectos envolvidos na discussão da resiliência regional, sobretudo do ponto de vista evolucionário.

Quando se busca responder quão resilientes tem sido as regiões aos choques recessivos, quando e em que medida as regiões recuperaram-se deles ou quando as trajetórias de crescimento foram permanentemente afetadas, envolve-se, de acordo com Fingleton et al. (2012), testar a existência de possíveis deslocamentos nas trajetórias de crescimento regional e taxas de crescimento regional.

Para uma análise exploratória inicial, Fingleton et al. (2012) propõem o uso de dois indicadores distintos. O Índice de Sensibilidade (IS) busca captar a resistência da região ao choque específico, sendo calculada pelo declínio percentual no emprego regional relativo ao emprego nacional durante a recessão. Uma região com um IS maior que a unidade pode ser considerada menos resistente a um choque recessivo nacional que uma região com um índice menor que a unidade.

$$
I S=\frac{\left(\frac{E_{i F}}{E_{i 1}}-1\right)}{\left(\frac{E_{B R F}}{E_{B R 1}}-1\right)}
$$

(1) Aplicações da metodologia para o Reino Unido, Itália e Turquia, respectivamente. 
Em que,

$E_{i F}$ : Emprego da região $i$ no último mês de recessão $\mathrm{t}=\mathrm{F}$.

$E_{i 1}$ : Emprego da região $i$ no mês inicial da recessão $t=1$.

$E_{B R F}$ : Emprego no Brasil no último mês da recessão $\mathrm{t}=\mathrm{F}$.

$E_{B R 1}$ : Emprego no Brasil no mês inicial da recessão $\mathrm{t}=1$.

O segundo indicador utilizado na análise exploratória sugerida por Fingleton et al. (2012) consiste no Índice de Recuperação do Emprego Regional, calculado como o crescimento percentual do emprego regional pós-recessão como proporção do crescimento percentual nacional. Neste caso, um IR maior que 1 (um) indica regiões com mais capacidade de recuperação pós-crise e IR menor que a unidade indica regiões com recuperação pós-crise inferior que a média nacional.

$$
I R=\frac{\Delta V E_{1}}{\Delta V E_{B K}}
$$

Em seguida, a estimação proposta se dá através do SUR (Seemingly Unrelated Regressions), ou Regressões Aparentemente Não-Relacionadas, seguindo a abordagem metodológica proposta por Finlgeton et al. (2012). De acordo com estes autores, o modelo SUR é bastante flexível e, apesar de as interdependências interregionais não estarem expressas explicitamente em uma função particular e parametrizada, além de não ser necessária a especificação (a priori) de uma matriz de pesos espaciais, o modelo permite ligações entre as unidades espaciais por serem deixadas indeterminadas como uma covariância geral no termo de erro, para cada equação de crescimento do emprego regional. Dessa maneira, um choque que afeta o crescimento do emprego em uma região pode afetar simultaneamente o crescimento do emprego em outras regiões (Fingleton et al., 2012). Neste trabalho, o pressuposto implícito para a utilização do modelo SUR é, segundo estes autores, que os efeitos espaciais que decorrem do componente do erro não observado no modelo não se devem a uma interação espacial direta - em que a taxa de crescimento do emprego em uma região i é uma resposta direta das taxas de crescimento do emprego nas regiões j e k.

Para Cellini e Torrisi (2014), o modelo é um útil ponto de partida analítico para identificar a capacidade de resiliência das regiões. Consiste, segundo eles, de uma análise de regressões bastante simples, permitindo verificar de que forma as regiões reagem e se recuperam de choques em diferentes formas. Ademais, conforme já ressaltado em Rodriguez-Fuentes e Padrón Marrero (2008), outra vantagem da estimação SUR é a sua eficiência no tratamento de dados de regiões heterogêneas.

Cellini e Torrisi (2014) ressaltam que esta metodologia permite a geração de algumas respostas para questões relevantes de uma maneira simples e intuitiva. 
Segundo eles, os resultados permitem responder se as regiões têm respondido ao mesmo choque da mesma forma; se elas têm se recuperado dos mesmos choques de formas semelhantes; quais são as que apresentam os maiores graus de resistência aos choques recessivos; quais delas são as mais aptas a se recuperarem; e se há alguma relação entre a performance de crescimento regional e a forma como elas reagem e se recuperam dos choques. Ademais, não se conseguem levantar informações suficientes a fim de captar as formas como as regiões se adaptaram e modificaram suas estruturas, ou se ainda estão em processo de adaptação e adaptabilidade.

Para o detalhamento da estrutura do modelo a ser testado, será adaptada a versão de Cellini e Torrisi (2014) para o modelo de Fingleton et al. (2012). As variáveis principais utilizadas são:

$y_{i t}: \log$ do nível de emprego ${ }^{2}$ na região i no tempo t.

$g_{i t}$ : primeira diferença de $y_{i t}$. Medida do crescimento do emprego.

$i=1,2 . . N$

$t=1,2, \ldots T$

$D_{k}$ : Variável dummy associada a cada choque recessivo $k . k=1,2 . . K$

$S_{k}$ : Variável dummy correspondente ao período pós-recessão, seguinte a cada choque ${ }^{3}$.

De posse das variáveis, o modelo a ser estimado de modo a captar os impactos diferenciados dos choques nas economias dos estados é o seguinte;

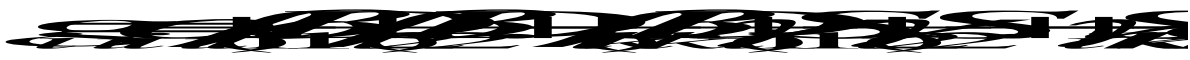

$\mathrm{Ou}$, de forma reduzida,

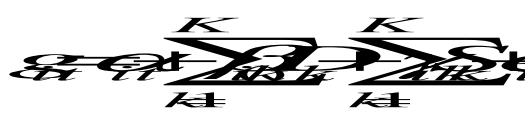

Em que,

$\alpha_{i t}$ : Taxa de crescimento autônoma do emprego.

$e_{i}:$ Termo de erro.

(2) Uma vez que o emprego formal, em nível e em índice, é não-estacionário, utilizou-se a variação do emprego formal com ajuste sazonal, que se mostrou estacionário para a grande maioria de estados brasileiros. Para os demais casos, a utilização de uma segunda diferença do emprego não iria gerar informações úteis para a análise que se propõe. Desta maneira, optou-se por proceder a estimação desta mesma forma, com esta ressalva.

(3) Fingleton et al. (2012) assumem que o período pós-crise dure até o choque subsequente. Entretanto, segundo Cellini e Torrisi (2014), pode-se assumir que o período pós-recessão tenha uma duração fixa. 
Através da estimação desta equação via SUR (Regressões Aparentemente Não Relacionadas) $)^{4}$, segundo os autores, tem-se a possibilidade de comparar os coeficientes $\beta$ e $\gamma$ entre as regiões. O coeficiente $\beta_{i(k)}$ mostra a reação da região $i$ ao choque $k$ e o coeficiente $\gamma_{i k}$ a recuperação da região $i$ ao choque $k$. A heterogeneidade entre os coeficientes $\beta_{i(k)}$ e $\gamma_{i k}$ referentes a um choque específico significa diferentes comportamentos de resiliência entre as regiões. Caso o coeficiente estimado ( $\beta$ ou $\gamma$ ) tenha valor zero, isto é, não seja significativo, dizse que não há efeito específico do choque $k$ sobre a região $i$.

O período utilizado para a estimação desta etapa da metodologia compreende os meses entre janeiro de 2000 a janeiro de 2014, em função da disponibilidade de dados por parte do Caged/MTE. Neste período, foram identificados três momentos de piora nas expectativas em relação à economia brasileira que mereceram intervenção da política econômica, por exemplo, com alterações na taxa de juros (cuja inflexão para baixo se deu a partir de 2009). Dessa forma, a equação a ser estimada neste trabalho terá $k=3$ choques testados, embora o nosso foco recaia apenas sobre o terceiro deles, a crise financeira global. Tomazzia e Meurer (2009) evidenciam que os dois primeiros momentos escolhidos como choques demandaram respostas específicas de política econômica por parte do governo federal, em virtude de seus efeitos recessivos sobre a economia nacional.

$D_{1}$ : Terceiro trimestre de 2001: período sob os efeitos da crise energética na economia brasileira, Crise da Argentina e efeitos sobre a economia mundial dos ataques terroristas de 11 de setembro nos Estados Unidos.

$D_{2}$ : Quarto trimestre de 2002: período de elevação nas incertezas quanto à economia brasileira com a eleição para presidente de Luis Inácio Lula da Silva, o chamado "Efeito Lula".

$D_{3}$ : Quarto trimestre de 2008: período dos impactos generalizados da crise financeira global sobre os estados brasileiros.

O método de estimação das equações do modelo acima, o SUR, é utilizado com regressores idênticos em todas as equações estaduais. Segundo Greene (2010), este é um caso comum em que o estimador por Mínimos Quadrados Generalizados é equivalente ao estimador da equação individual por Mínimos Quadrados Ordinários.

Para a observação dos impactos da crise financeira, serão definidos como indicadores de atividade econômica, as informações sobre produção e emprego. A

(4) De acordo com Fingleton et al. (2012), ao proceder-se uma estimação deste tipo, não se tem interesse em quão bem o modelo SUR irrestrito se ajusta aos dados para cada região. O objetivo do exercício, segundo ele, é a comparação entre as regiões que o modelo possibilita. 
Variação no Emprego Formal foi obtida através do Cadastro Geral de Empregados e Desempregados (Caged), do Ministério do Trabalho e Emprego, por meio do saldo entre as séries de admissões e desligamentos ocorridos em cada mês. Utilizando os dados da Relação Anual de Informações Sociais (RAIS) sobre o total de empregos no mês de dezembro de 2003, gerou-se uma série aproximada do nível de emprego formal mensal em cada estado. A partir do nível de emprego formal mensal aproximado pelas equações acima, gerou-se um Índice de Emprego Formal ${ }^{5}$.

A variação do emprego formal e, consequentemente, o Índice do Emprego Formal apresentam, em geral, forte componente sazonal e, por isso, todas as séries foram ajustadas pelo programa X12-ARIMA, desenvolvido pelo United States Census Bureau. O componente sazonal das séries de emprego é bastante conhecido na literatura econômica.

\section{Resistência e recuperação econômica dos estados brasileiros aos efeitos da crise financeira global}

Adotando o instrumental sugerido por Fingleton et al. (2012), seguido por Cellini e Torrisi (2014), Di Caro (2014) e Eraydin (2016), analisará as respostas diferenciadas dos estados brasileiros para a crise financeira de 2008. A figura abaixo evidencia o impacto que a crise financeira teve sobre o emprego formal no Brasil entre o último trimestre de 2008 e o primeiro trimestre de 2009, com um grau de demissões bem mais elevado que o comum para o período, cuja diferença fica ainda mais evidente na série de variação no emprego ajustada para corrigir a sazonalidade, recorrentes nas séries de emprego. É importante destacar que o Brasil registrou a menor queda percentual no emprego $(0,7 \%)$ durante a crise, se comparado com todos os outros países em que se têm informações disponíveis, segundo a Organização Internacional do Trabalho (2010). A recuperação do emprego foi rápida, também de acordo com o órgão, tendo início antes mesmo que o PIB e recuperando os níveis de emprego anteriores à crise já no mês de novembro de 2009. Os comportamentos das séries de variação estadual no emprego, por sua vez, são consideravelmente diversos e em função das diferenças em relação à escala.

(5) A opção pelo Índice de Emprego, ao invés da variação absoluta, obtida diretamente das séries do Caged, ou do nível construído via a interação desta série com as informações da RAIS, se justifica, sobretudo por dois pontos. Ao utilizar o índice ou o nível de emprego, podem-se incluir tais variáveis no modelo aplicando-se os respectivos logaritmos, de forma a reduzir as suas variâncias. Tal operação não é possível de ser aplicada na Variação do Emprego Formal, que apresenta valores negativos. Em segundo lugar, a utilização das variáveis em Índices reduz as discrepâncias existentes em termos absolutos na quantidade e variação do emprego entre os estados, facilitando a comparação entre eles. O Índice do Emprego Formal (IEmprego) tem como período base janeiro de 2008, ano de início dos impactos da crise financeira nos estados brasileiros. 
Figura 1

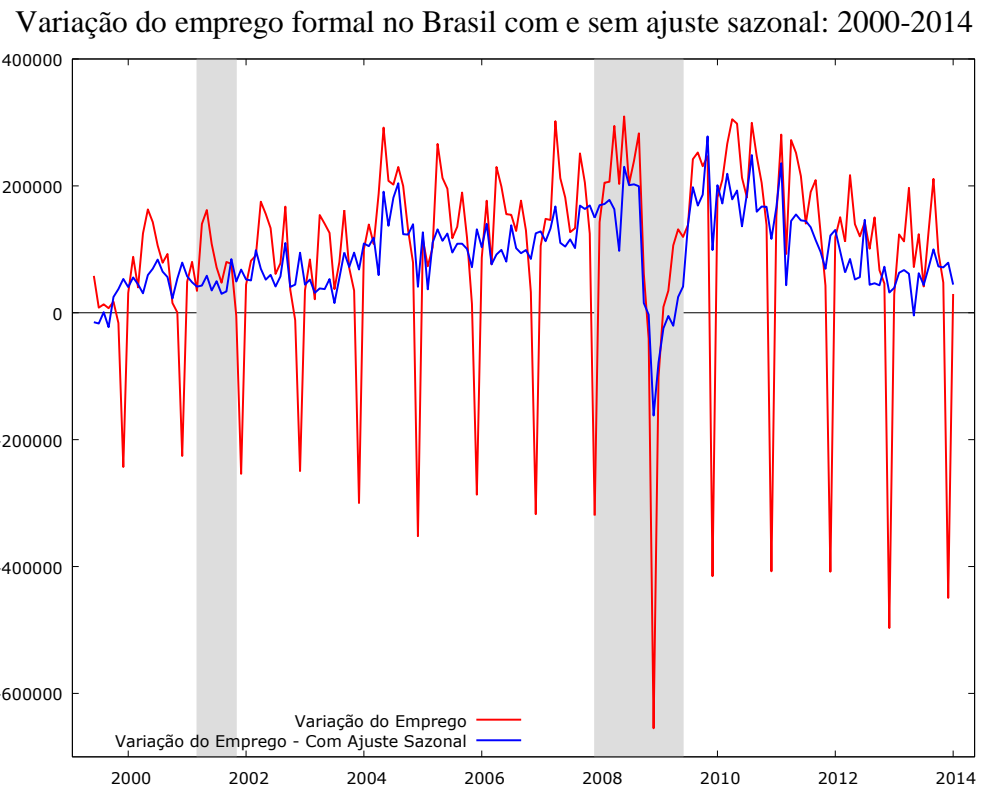

Fonte: Elaboração própria com base nos dados do Caged/MTE.

No segundo e terceiro trimestre do ano de 2008, momento no qual a crise financeira adquire dimensões sistêmicas (OIT, 2010), as taxas de variação no emprego formal começaram a cair, de forma generalizada, em todos os estados brasileiros. Entretanto, é a partir do quarto trimestre deste ano que se verificam quedas no número de empregos formais em todos os estados, mas com durações e intensidades distintas. Para o período considerado neste trabalho, a economia brasileira - como um todo - apresentou redução no emprego formal por apenas três meses (de novembro de 2008 a janeiro de 2009). Todavia, este efeito sobre alguns estados iniciou-se meses antes e prolongou-se por alguns meses depois, como é o caso evidente de Alagoas, Maranhão, Rio Grande do Norte e dos estados do Amazonas, Pará e Minas Gerais (em menor grau, relativamente aos primeiros), que também se destacam na análise da redução da atividade quando se analisa a produção industrial, na seção seguinte.

Uma análise exploratória sobre alguns aspectos das respostas dos estados a esse choque específico será realizada através de dois indicadores propostos por Fingleton et al. (2012): i. Índice de Sensibilidade e ii. Índice de Recuperação ao choque recessivo. Conforme já apresentado, o indicador de resistência busca captar a sensibilidade da economia regional ao choque, sendo calculado pela razão entre o declínio percentual no emprego regional durante a recessão e o declínio no emprego nacional durante a recessão. Uma região com um Índice de Sensibilidade maior que a unidade pode ser considerada menos resistente aos efeitos contemporâneos de um 
choque recessivo nacional que uma região com um índice menor que a unidade (Fingleton et al., 2012).

A Tabela 1 em seguida mostra o impacto da crise financeira sobre o emprego formal nos estados brasileiros no final do ano de 2008 e início do ano de 2009 e apresenta os valores do indicador de sensibilidade ao choque. Podem-se apontar, a priori, três níveis de impactos imediatos diferenciados do choque recessivo sobre os estados brasileiros: i. Há diferenças consideráveis na intensidade da retração no emprego entre os estados; ii. A duração da recessão difere entre os estados; e, iii. O início dos impactos do choque recessivo não é o mesmo para todos os estados. Essa percepção está de acordo com os resultados de Braatz (2013) que, estudando as assimetrias nas respostas dos estados brasileiros a um choque monetário comum, constata acentuadas diferenças nos impactos e na temporalidade das respostas.

Tabela 1

\begin{tabular}{|c|c|c|c|c|}
\hline $\begin{array}{l}\text { Nível } \\
\text { Geográfico }\end{array}$ & Período de Queda & $\begin{array}{c}\text { Duração da } \\
\text { Queda } \\
\text { (Meses) }\end{array}$ & $\begin{array}{l}\text { Queda Total no } \\
\text { Emprego }(\%)\end{array}$ & $\begin{array}{l}\text { Indicador de } \\
\text { Sensibilidade }\end{array}$ \\
\hline Amazonas & 2008.10 a 2009.05 & 8 & $-8,57$ & 3,40 \\
\hline Tocantins & 2008.10 a 2008.01 & 4 & $-5,84$ & 2,32 \\
\hline Rio Grande do Norte & 2008.11 a 2009.05 & 7 & $-5,74$ & 2,28 \\
\hline Minas gerais & 2008.10 a 2009.02 & 5 & $-5,16$ & 2,05 \\
\hline Pará & 2008.11 a 2009.05 & 5 & $-4,99$ & 1,98 \\
\hline Maranhão & 2008.11 a 2009.06 & 8 & $-4,62$ & 1,83 \\
\hline Espirito Santo & 2008.11 a 2009.02 & 4 & $-2,76$ & 1,10 \\
\hline Brasil & 2008.11 a 2009.01 & 3 & $-2,52$ & 1 \\
\hline Rondônia & 2008.12 & 1 & $-1,99$ & 0,79 \\
\hline Piauí & 2008.12 a 2009.02 & 3 & $-1,58$ & 0,63 \\
\hline Ceara & 2008.12 a 2009.02 & 3 & $-1,63$ & 0,65 \\
\hline Sergipe & 2008.12 a 2009.05 & 6 & $-1,33$ & 0,53 \\
\hline Roraima & 2008.12 & 1 & $-1,10$ & 0,44 \\
\hline São Paulo & 2008.11 a 2009.02 & 3 & $-3,26$ & 1,30 \\
\hline Paraná & 2008.11 a 2008.12 & 2 & $-2,35$ & 0,93 \\
\hline Santa Catarina & 2008.12 & 1 & $-1,77$ & 0,70 \\
\hline Rio Grande do Sul & 2008.12 & 1 & $-1,31$ & 0,52 \\
\hline Mato Grosso do Sul & 2008.11 a 2008.12 & 2 & $-4,53$ & 1,80 \\
\hline Mato Grosso & 2008.10 a 2008.12 & 3 & $-5,06$ & 2,01 \\
\hline Goiás & 2008.10 a 2008.12 & 3 & $-3,87$ & 1,53 \\
\hline Distrito Federal & 2008.12 a 2009.01 & 2 & $-0,78$ & 0,31 \\
\hline
\end{tabular}

Fonte: Elaboração Própria a partir dos dados do Caged/MTE. 
O caso do Amazonas é o primeiro que chama a atenção por ter sido um dos estados que primeiro refletiu o choque da crise financeira, o que pode ser compreendido por ter apresentado uma das maiores reduções na atividade econômica e a maior duração dos impactos negativos do choque recessivo, tanto com relação à variação negativa do emprego, quanto na redução na atividade industrial (analisada no próximo tópico). Tal fato pode ser atribuído às especificidades na conformação de sua economia e o peso que o setor manufatureiro, sobretudo na ou por causa da Zona Franca de Manaus. Trabalhos como o de Fingleton et al. (2012) e Davies (2011) apontam, em seus resultados, fortes impactos da crise sobre regiões industriais como Manaus. De fato, a análise setorial da redução do emprego no estado evidencia que a indústria de transformação foi a principal responsável pela redução do emprego amazonense entre os últimos meses de 2008 e primeiros meses de 2009. Infere-se que a indústria de transformação no estado foi duramente atingida pela combinação de uma redução no crédito e contração da demanda internacional, sobretudo em relação aos impactos iniciais, e pela redução na demanda nacional, que parece ter ampliado a duração dos efeitos recessivos da crise, mesmo após a inflexão da política monetária e creditícia do governo federal.

O Maranhão e o Rio Grande do Norte apresentaram duração do choque semelhante à do Amazonas. Especificamente no caso do Maranhão, parte deste choque está relacionado ao peso da extração mineral no Estado, que potencializa o efeito do choque diante de uma retração da demanda internacional. Neste grupo de estados nos quais o choque se prolongou por um período maior de tempo, destacamse ainda os casos de Minas Gerais e Pará, nos quais se verifica um impacto significativo dos setores voltados à exportação (em especial, a produção de minério e outras atividades ligadas à atividade extrativa), o que aprofundou a transmissão da crise para o emprego formal. No Pará, por exemplo, destaca-se também a retração na indústria madeireira e, em Minas, nas indústrias de metalurgia e automobilística. A dependência da base industrial em relação ao setor externo também parece explicar o caso da redução do emprego no Espírito Santo, cujo resultado será mais bem detalhado no item sobre o produto industrial. Além dos casos acima, dentre os estados tidos como mais sensíveis, ou menos resistentes aos efeitos do choque, nesta primeira análise exploratória, identificam-se impactos agudos da crise em São Paulo, Espírito Santo e Tocantins ${ }^{6}$.

A análise da Tabela 1 também permite inferir que Rio de Janeiro, Distrito Federal, Rondônia e Roraima, Ceará, Piauí, Sergipe e os três estados da Região Sul foram os mais resistentes aos efeitos do choque recessivo provocado pela crise

(6) Apesar de Alagoas e Acre terem apresentado um resultado do indicador que os colocaria como estados pouco resistentes, uma análise complementar do comportamento da série dessazonalizada das respectivas variações no emprego formal indica que deve-se atribuir tais resultados a variações sazonais e não aos impactos da crise financeira. 
financeira global, nas duas formas de tratar o índice de resistência proposto. De todo modo, tal resultado não significa de modo algum que tais estados tenham saído imunes aos efeitos desta crise. Apesar da redução no emprego consideravelmente menor que a média nacional, durante o período da crise, o choque recessivo interrompeu períodos de intensa criação de vagas de emprego formal que estavam em curso no Rio de Janeiro, na Bahia, no Ceará e nos estados do Sul. Merece destaque, no caso destes estados, que a interrupção no ciclo de crescimento na criação de empregos é acompanhada por uma tendência de criação de emprego decrescente no pós-crise. Em se tratando de resiliência, a mudança na trajetória de crescimento do emprego pode indicar efeitos de longo prazo do choque sobre as economias regionais, mas estas alterações não são captadas de forma satisfatória nesta análise.

Ainda em relação aos estados tomados aqui como menos sensíveis ao choque recessivo, destacam-se aqueles que, de fato, não parecem ter sofrido fortes impactos ou variações que fujam de uma tendência de crescimento do emprego em curso diante do choque, como é o caso de Roraima Rondônia, Distrito Federal, Paraíba, Sergipe e Piauí. Em relação a esses estados, ressalta-se que a maior parte deles, com exceção do Distrito Federal, tem estruturas pouco diversificadas em termos de atividade econômica, mas ao mesmo tempo, com menor inserção internacional, o que pode ter reduzido as respectivas exposições aos efeitos da queda no comércio internacional. Além disso, são estados em que o peso do setor informal é mais elevado, de forma que os dados utilizados nesta análise não conseguem captar esta dinâmica.

Em relação ao Distrito Federal, o peso dos empregos do setor público sobre o total do emprego formal nesta unidade da federação é bastante elevado, explicando em grande parte a estabilidade do comportamento desta variável mesmo durante a crise financeira internacional. De fato, como aponta Blazek e Netrdová (2012), regiões que apresentam muitas instituições do setor público e grande variedade de empresas do setor de serviços tendem a ser menos afetadas pelos choques. As instituições do setor público são grandes empregadoras em capitais e, mesmo que ocorram quedas na disponibilidade de recursos financeiros durante a crise no setor público, ela não é tão intensa quanto ocorre no setor privado (Blazek; Netrdová, 2012). Além disso, ressalta-se que grande parte dos trabalhadores do setor público tem sua estabilidade garantida pela legislação vigente. Portanto, este resultado traduz a estabilidade do emprego do setor público presente nesta unidade da federação.

O segundo indicador proposto por Fingleton et al. (2012) consiste no Índice de Recuperação, calculado como a razão entre o crescimento percentual do emprego regional no período pós-recessão e o crescimento percentual do emprego nacional no mesmo período. Por sua vez, as regiões com Índice de Recuperação maior que a 
unidade se recuperaram de forma mais acentuada do que aquelas que apresentaram Índice de Recuperação menor que $1,00^{7}$.

Tabela 2

Recuperação do Emprego Regional nos Estados Brasileiros: Índice de Recuperação à Crise do Subprime

\begin{tabular}{|c|c|c|c|c|}
\hline Nível Geográfico & $\begin{array}{c}\text { Índice de } \\
\text { Recuperação } \\
(1 \text { ano })\end{array}$ & $\begin{array}{c}\text { Índice de } \\
\text { Recuperação } \\
(2 \text { anos })\end{array}$ & $\begin{array}{c}\text { Índice de } \\
\text { Recuperação } \\
\text { anos })\end{array}$ & $\begin{array}{c}\text { Índice de } \\
\text { Recuperação } \\
(4 \text { anos })\end{array}$ \\
\hline Brasil & 1,00 & 1,00 & 1,00 & 1,00 \\
\hline Rondônia & 4,43 & 2,52 & 1,90 & 1,23 \\
\hline Acre & 0,87 & 0,51 & 0,42 & 0,30 \\
\hline Amazonas & 0,03 & 0,76 & 1,20 & 1,05 \\
\hline Roraima & 1,40 & 1,10 & 0,86 & 0,69 \\
\hline Pará & 0,43 & 0,79 & 0,96 & 1,03 \\
\hline Amapá & 0,16 & 0,49 & 0,88 & 1,00 \\
\hline Tocantins & 0,91 & 0,78 & 0,67 & 0,49 \\
\hline Maranhão & $-0,33$ & 0,70 & 0,74 & 0,52 \\
\hline Piauí & 1,91 & 1,52 & 1,22 & 1,18 \\
\hline Ceará & 2,01 & 1,61 & 1,45 & 1,55 \\
\hline Rio Grande do Norte & 0,37 & 0,83 & 0,88 & 0,95 \\
\hline Paraíba & 1,29 & 1,16 & 1,33 & 1,52 \\
\hline Pernambuco & 1,41 & 1,43 & 1,50 & 1,46 \\
\hline Alagoas & 0,62 & 0,51 & 0,69 & 0,60 \\
\hline Sergipe & 1,50 & 1,38 & 1,34 & 1,44 \\
\hline Bahia & 1,72 & 1,18 & 1,04 & 0,89 \\
\hline Minas Gerais & 0,89 & 1,09 & 1,09 & 1,07 \\
\hline Espirito Santo & 0,96 & 0,86 & 0,94 & 0,97 \\
\hline Rio de Janeiro & 0,79 & 0,90 & 0,97 & 0,98 \\
\hline São Paulo & 0,85 & 0,92 & 0,92 & 0,89 \\
\hline Paraná & 1,05 & 0,99 & 1,02 & 1,11 \\
\hline Santa Catarina & 1,22 & 0,97 & 0,96 & 1,13 \\
\hline Rio Grande do Sul & 1,06 & 1,07 & 1,06 & 1,15 \\
\hline Mato Grosso do Sul & 1,07 & 0,85 & 0,78 & 0,86 \\
\hline Mato Grosso & 0,82 & 0,53 & 0,57 & 0,79 \\
\hline Goiás & 1,41 & 1,12 & 1,03 & 1,11 \\
\hline Distrito Federal & 0,95 & 0,73 & 0,64 & 0,56 \\
\hline
\end{tabular}

Fonte: Elaboração própria com base nos dados do Caged/MTE.

(7) Neste indicador, uma questão que deve ser destacada é a dificuldade de se estabelecer ad hoc um período fixado para a mensuração desta recuperação. Fingleton et al. (2014) usam como período de recuperação o crescimento do emprego até o início de uma outra recessão. Cellini e Torrisi (2014), por outro lado, estabelecem um limite de três anos após o choque como sendo o período máximo para a ocorrência da recuperação. No caso deste trabalho, não há uma outra recessão evidente após a crise de 2008-2009, o que levaria à utilização de todo o período pós-crise nos dados disponíveis, no caso, quatro anos após o ponto mais agudo da crise, maior que o período utilizado por Cellini e Torrisi (2014), portanto. Entretanto, de forma a minimizar a imprecisão relacionada com a definição da duração do período pós-crise, o Índice de Recuperação será calculado para mais de um período do pós-crise: 1 , 2,3 e 4 anos após o auge dos impactos do choque recessivo. 
Há, neste caso, um padrão diferente ao encontrado por Fingleton et al. (2012), em que algumas das regiões mais afetadas pela crise foram as que mais bem se recuperaram, em termos de variação percentual no emprego. No Brasil, os estados do sul - Paraná, Rio Grande do Sul e Santa Catarina - aparecem, nos indicadores acima, como os estados que menos foram impactados num primeiro momento pela crise ao mesmo tempo que foram os que mais se recuperaram. Este também é o caso do estado de Rondônia, na Região Norte.

Destaca-se, ainda, que no caso brasileiro, as regiões mais sensíveis ao choque foram, em geral, as que pior se recuperaram dele nos períodos subsequentes. Entre os estados mais atingidos pela crise, de acordo com o Indicador de Sensibilidade, o Maranhão e o Rio Grande do Norte se destacam como os de pior recuperação ao choque entre todos, nos quatro períodos observados. Além disso, em ambos os estados acima o setor informal, não captado aqui, é bastante representativo. Destaca-se que o Maranhão tem uma economia pouco diversificada no que tange aos setores geradores de emprego formal.

O Amazonas, estado em que os efeitos da crise se manifestaram primeiro, por mais tempo e em grande intensidade, tem uma recuperação diferente nos períodos analisados. Nos dois primeiros anos do pós-crise o estado apresenta taxas de crescimento do emprego menores que a média do Brasil, mas passando a apresentar um índice de recuperação maior ao fim do terceiro e do quarto ano após o auge dos efeitos da crise financeira. Tal resultado é compreensível uma vez que o Amazonas foi afetado por uma queda de grande intensidade e de duração maior no emprego, fazendo com que as taxas acumuladas de recuperação demorem a apresentar resultados positivos.

O comportamento da recuperação do emprego nos estados brasileiros no pós-choque mostra-se, contudo, bem mais homogêneo do que o do emprego durante o período de recessão. Nesse sentido, os valores se encontram mais bem distribuídos em torno de 1, com poucos valores mais extremos. Mais uma vez evidencia-se que o Distrito Federal apresenta um comportamento mais estável do mercado de trabalho em função da participação do setor público. A fim de confirmar tais considerações a partir da análise exploratória realizada acima, parte-se para a análise do modelo proposto por Fingleton et al. (2012) e Celline e Torrisi (2014) de maneira a comparar as respostas dos estados brasileiros ao choque recessivo da crise do subprime. Os resultados da estimação do Modelo SUR encontram-se no Anexo deste trabalho.

Não se tem como objetivo comparar os efeitos da crise do subprime com os outros momentos de piora nas expectativas considerados no modelo estimado. Dessa forma, este trabalho irá se ater aos resultados dos parâmetros relacionados com o choque de 2008/2009 e sua recuperação. Ademais, assim como Fingleton et al. (2012) ressaltam, não se tem interesse aqui no poder de explicação do modelo 
estimado, mas sim na significância dos parâmetros estimados e na comparação entre os parâmetros significativos.

Os resultados mostrados na Tabela 2 confirmam a análise que já vinha sendo realizada na parte descritiva dos indicadores de Sensibilidade e Resistência e da análise do comportamento das séries de tempo de variação no emprego formal dessazonalizado. As diferenças de significância dos parâmetros relativos às variáveis dummy dos choques e dos períodos de recessão indicam que, de fato, há uma heterogeneidade considerável em como choques recessivos nacionais são distribuídos espacialmente entre as regiões brasileiras. Verificou-se a presença daquelas nas quais o impacto destas crises não mostrou-se significativo, isto é, estados que não foram afetados de maneira específica pelos choques em seu momento mais grave, apesar de a redução na atividade econômica ter ocorrido, como mostrado na análise descritiva.

Nos estados nos quais os parâmetros para o choque se mostraram significativos, a evidência que se observa é que, durante o período mais intenso dos impactos da crise, tais localidades foram afetadas diretamente por seus efeitos, tendo consequências diretas sobre a variação no emprego formal, isto é, sobre a dinâmica das demissões e contratações nas economias regionais.

Em geral, como esperado, o sinal dos parâmetros estimados estatisticamente significativos foi negativo (com exceção do resultado para Pernambuco) indicando que, nesses estados, o período correspondente ao auge dos efeitos da crise do subprime sobre a economia brasileira é marcado por uma redução na quantidade de empregos no país. Assim, nesses estados em específico, há uma redução nas contratações de mão-de-obra e aumento no volume de demissões evidenciando os impactos da crise financeira global para a dinâmica real da economia de alguns estados brasileiros.

A relação expressa a partir dos parâmetros significativos para o choque recessivo da crise do subprime, corroboram com as primeiras análises da resiliência baseada na trajetória do emprego formal, em que Amazonas (-1,92787), Pará $(-1,63480)$, Minas Gerais $(-1,33629)$, Espirito Santo $(-1,18774)$ e São Paulo $(-1,04523)$ despontam, definitivamente, como os estados com maior sensibilidade ao choque recessivo de 2008 e 2009 . Este padrão de impactos sobre estes estados brasileiros já vinha sendo evidenciado desde o início das análises aqui realizadas.

O maior impacto da crise em tais estados parece ter uma relação com a forma como as estruturas produtivas locais estão postas, o que potencializa os canais de transmissão do choque. Por exemplo, o forte impacto da última crise financeira para o Amazonas deve-se a uma série de fatores: à maior concentração do setor industrial no Amazonas (em grande parte, é representada pela Zona Franca de Manaus), à instabilidade cambial, à redução da demanda externa, às mudanças nas expectativas 
dos agentes e, também, à forte dependência das firmas e atividades produtivas locais do mercado externo. Este é o caso do Espírito Santo, Minas Gerais e Pará (onde a atividade mineradora exerce grande influência sobre as estruturas produtivas locais). Os mecanismos de transmissão monetários se propagam muito rapidamente após um choque, principalmente em função da alta integração dos sistemas financeiros locais e das respectivas dinâmicas do mercado financeiro global - o que ajuda a entender o caso de São Paulo.

Os parâmetros correspondentes ao período de recuperação do choque também mostraram, em regra, o sinal esperado. Assim, pôde-se verificar como o período pós-crise teve comportamentos diferentes entre os estados brasileiros. Entretanto, as diferenças na recuperação não se mostram tão discrepantes, com apenas dois valores superiores à unidade (Ceará e Rondônia) que, dada a padronização das variáveis, implica em uma variação superior a um desvio-padrão.

A heterogeneidade verificada em relação às significâncias e valores dos coeficientes $\beta$ e $\gamma$ estimados para o choque recessivo de 2009/2009 e, de forma complementar, a análise exploratória realizada com ajuda dos índices de Sensibilidade e Recuperação ao choque, corroboram a hipótese de que há, de fato, diferentes comportamentos de resiliência econômica nos estados brasileiros, quando se leva em conta o mercado de trabalho formal.

\section{Considerações finais}

O objetivo deste artigo foi analisar os impactos diferenciados da crise financeira global, iniciada com o episódio das hipotecas do subprime nos Estados Unidos, sobre os estados brasileiros. Nesse aspecto, a discussão realizada buscou estudar os padrões diferenciados de resistência e recuperação da atividade econômica, a partir do comportamento do emprego formal e da produção industrial. Em questões teóricas, o foco deste artigo foi a análise de como os efeitos de um choque recessivo podem espalhar-se de forma desigual entre diferentes regiões. Portanto, o objetivo do segundo tópico deste trabalho foi trazer a questão regional para as discussões sobre os efeitos da crise financeira, sobretudo a respeito das capacidades diferenciadas que as regiões apresentam em lidar com choques que atinjam seus sistemas econômicos. Para isso, a discussão sobre impactos regionais de crises financeiras do tópico dois deste artigo introduziu a questão da resiliência econômica regional. A incorporação dessa discussão relativamente nova na literatura de economia regional busca agregar à discussão da transmissão regional dos choques monetários a noção de que as regiões apresentam capacidades distintas para lidar com choques e rupturas, em vários âmbitos que dizem respeito ao processo de desenvolvimento regional. 
A construção dos indicadores de Sensibilidade e Recuperação do emprego estadual aos efeitos da crise financeira global, complementados pela estimação da "Equação de Resiliência” proposta por Fingleton et al. (2012) permitiram uma análise dos diferentes padrões de respostas dos estados brasileiros à crise financeira global, de forma a identificar os estados mais afetados.

Os resultados da análise da Resistência e da Recuperação dos estados brasileiros à crise evidenciam que, de fato, as regiões brasileiras diferem nas formas em que respondem a choques comuns. Os resultados indicam, também, que os estados mais resistentes à crise financeira não são, necessariamente, os que apresentam uma maior tendência de crescimento no pós-crise. Diferente do que se esperava, os estados economicamente mais frágeis não foram, via de regra, os estados menos resistentes ao choque recessivo. Nesse aspecto, a maior sensibilidade dos estados aos efeitos da última crise financeira deu-se, sobretudo, no Amazonas, em decorrência da queda na sua indústria de transformação e em outros estados cuja dinâmica local é bastante influenciada pela dinâmica externa, através de suas exportações, principalmente de commodities e de atividades ligadas à extração, como Minas Gerais, Espírito Santo e Pará.

Entretanto, o escopo deste estudo não esgota a ampla agenda de pesquisa relacionada aos impactos regionais da crise financeira. A considerável restrição na disponibilidade de dados sobre vários outros aspectos da atividade econômica dos estados e o período relativamente curto desde o final da recessão impõem importantes limitações sobre a análise realizada. A primeira delas diz respeito às proxies relacionadas à atividade econômica. A adoção da variação do emprego formal ignora uma série de impactos sobre o setor informal e o mercado de trabalho pode não reagir de forma tão rápida quanto a produção.

Uma outra limitação surge do método de análise de resiliência regional adotada neste trabalho. Ao optar pela análise da resistência e da recuperação do emprego no curto-prazo, devido a restrições similares às citadas no parágrafo anterior, reconhece-se que o trabalho não fornece respostas sobre importantes questões na construção da resiliência das regiões, principalmente em relação à adaptação e a adaptabilidade dos sistemas econômicos regionais - que são conceitoschave na concepção evolucionária do termo. Portanto, estudos mais aprofundados, que levantem questões estruturais e de longo prazo mais adequadas, com informações mais completas, para a análise da adaptação e da adaptabilidade dos sistemas econômicos estaduais, são necessários para verificar se as regiões mais resistentes, ou seja, com maior recuperação do emprego nos primeiros anos do póscrise são, de fato, as mais resilientes dentro da concepção que acredita-se ser a mais adequada. 
Por fim, fica evidente a necessidade de uma melhor compreensão das diferenças existentes nas respostas que as regiões são capazes de apresentar frente a choques comuns. Dessa maneira, ao aliar à política macroeconômica as implicações regionais das suas intervenções, o governo incorpora a possibilidade de mitigar os efeitos das crises naquelas regiões que se mostram mais vulneráveis, evitando assim um eventual aprofundamento das desigualdades regionais.

\section{Referências bibliográficas}

AMADO, A. M. Limites monetários ao crescimento: Keynes e a não neutralidade da moeda. Ensaios FEE, v. 21, p. 44-82, 2000.

BAILEY, David; BERKELEY, Nigel. Regional responses to recession: the role of the west midlands regional taskforce. Regional Studies, v. 48, n. 11, p. 1797-1812, 2014.

BAILEY, David, PROPRIS, Lisa de. Editorial: recession, recovery and resilience? Regional Studies, v. 48, n. 11, p. 1757-1760, 2014.

BLAZEK, Jirí, NETRDOVÁ, Pavlína. Regional unemployment impacts of the global financial crisis in the new member states of the EU in Central and Eastern Europe. European Urban ande Regional Studies, v. 19, n. 1, p. 42-61, 2012.

BRAATZ, Jacó. Impactos regionais assimétricos das políticas monetária e cambial no Brasil: uma abordagem com o método VAR. 2013. 90f. Dissertação (Mestrado em Economia)-Pontifícia Universidade Católica do Rio Grande do Sul, Porto Alegre, 2013.

BRISTOW, G. Resilient regions: re-'place'ing regional competitiveness. Cambridge Journal of Regions, Economy and Society, v. 3, n. 1, p. 153-167, 2010.

CAVAlCANTE, Anderson; CROCCO, Marco; JAIME JR. Frederico G. Preferência pela liquidez, sistema bancário e disponibilidade de crédito regional. In: CROCCO, Marco; JAIME JR., Frederico G. (Orgs.). Moeda e território: uma interpretação da dinâmica regional brasileira. Belo Horizonte: Autêntica, 2006. p. 295-315.

CELLINI, Roberto; TORRISI, Gianpiero. Regional resilience in Italy: a very longrun analysis. Regional Studies, v. 48, n. 11, p. 1779-1796, 2014.

CHRISTOPHERSON, Susan; MICHIE, Jonathan; TYLER, Peter. Regional resilience: theroretical and empirical perspectives. Cambridge Journal of Regions, Economy and Society, v. 3, p. 3-10, 2010.

CROCCO, M. Centralidade e hierarquia do sistema financeiro brasileiro. Nova Economia, v. 22, n. 1, p. 31-79, 2012. 
CROCCO, Marco. Moeda e desenvolvimento regional e urbano: uma leitura keynesiana e sua aplicação ao caso brasileiro. Tese (Concurso de Professo Titular) Departamento de Ciências Econômicas, Universidade Federal de Minas Gerais, abr. 2010.

DAVIES, Sara. Regional resilience in the 2008-2010 downturn: comparative evidence from European countries. Cambridge Journal of Regions, Economy and Society, n. 4, p. 369-382, 2011.

DI CARO, Paolo. Recessions, recoveries and regional resilience: evidence on Italy. Cambridge Journal of Regions, Economy and Society (Online), Dec. 2014.

DOW, S. C. Money and regional development. Studies in Political Economy, v. 23, n. 2, p. 73-94, 1987.

DOW, Sheila. Money and the economic process. Cambridge: Edward Elgar, 1993.

DOW, Sheila; RODRIGUES-FUENTES, Carlos J. Regional finance: a survey. Regional Studies, v. 31, n. 9, p. 903-920, 1997.

DOW, Sheila; RODRIGUES-FUENTES, Carlos J. Um “survey” da literatura de finanças regionais. In: CROCCO, Marco; JAIME JR., Frederico G. (Org.). Moeda e território: uma interpretação da dinâmica regional brasileira. Belo Horizonte: Autêntica, 2006. p. 39-75.

ERAYDIN, Ayda. Attributes and characteristics of regional resilience: defining and measuring the resilience of Turkish regions. Regional Studies, v. 50, n. 4, p. 600614, 2016.

FINGLETON, Bernard; GARRETSEN, Harry; MARTIN, Ron. Recessionary shocks and regional employment: evidence on the resilience of U.K. regions. Journal of Regional Science, v. 52, n. 1, p. 109-133, 2012.

FRANCIS, Neville; OWYANG, Michael; SEKHPOSIAN, Tatevik. The local effects of monetary policy. The BE Journal of Macroeconomics, v. 2, n. 41, p. 1-38, 2012.

FREITAS, M. C. P de. Os efeitos da crise global no Brasil: aversão ao risco e preferência pela liquidez no mercado de crédito. Estudos Avançados, São Paulo, v. 23, n. 66, 2009.

HULKA, J. Vztah vývoje regionální diferenciace a hospodářského cyklu: Teoretická diskuse a empirický důkaz. Ekonomický Časopis, v. 55, n. 10, p. 989-1006, 2007.

KRUGMAN, P. A crise de 2008 e a economia da depressão. Rio de Janeiro: Elsevier, 2009. 
LEE, Neil. Grimdown South? The determinants of unemployment Increases in British cities in the 2008-2009 Recession. Regional Studies, v. 48, n. 11, p. 1761$1778,2014$.

MORALES, Lucía; O’CALLAGHAN, Bernadette Andreosso. The global financial crisis: world market or regional contagion effects? International Review of Economics and Finance, n. 29, p. 108-131, 2014.

ORGANIZAÇÃO INTERNACIONAL DO TRABALHO, OIT. Brasil: Uma estratégia inovadora alavancada pela renda. Genebra: OIT, Instituto Internacional de Estudos do Trabalho, 2010. 138p.

PIKE, A.; DAWLEY; S.; TOMANEY, J. resilience, adaptation and adaptability. Cambridge Journal of Regions, Economy and Society, n. 3, p. 59-70, Jan. 2010.

RODRIGUEZ-FUENTES, Carlos Javier; PADRÓN-MARRERO, David. Industry effects of monetary policy in Spain. Regional Studies, v. 42, n. 3, p. 375-384, 2008.

SILVA, Fernanda Faria. Centralidade e impactos regionais de política monetária: um estudo dos casos brasileiro e espanhol. Tese (Doutorado)-Cedeplar/UFMG, 2011.

SIMMIE, James; MARTIN, Ron. The economic resilience of regions: towards an evolutionary approach. Cambridge Journal of Regions, Economy and Society, n. 3, p. 27-43, 2010.

TOMAZZIA, Eduardo Cardeal; MEURER, Roberto. O mecanismo de transmissão da política monetária no Brasil: uma análise em VAR por setor industrial. Economia Aplicada, v. 13, n. 4, p. 371-398, 2009.

WÓJCIK, D. The dark side of NY_LON: financial centres and the global financial crisis. Urban Studies, v. 50, n. 13, p. 2736-2752, 2013. 
Resiliência e impactos regionais de crises financeiras: uma análise para os estados brasileiros - 2007/08

\section{Anexo}

Tabela A.1

Resultados da Estimação por SUR

(Regressões Aparentemente Não Relacionadas) para a Equação de Resiliência

\begin{tabular}{|c|c|c|c|c|c|c|c|c|c|c|c|c|c|c|}
\hline & $\alpha$ & & $\beta 1(20$ & & $\beta 2(200$ & & $\beta 3(2008 / 2$ & 09) & $\gamma 1(2001$ & & $\gamma 2(200$ & & $\gamma 3(2008 / 2$ & 09) \\
\hline \multirow{2}{*}{$\mathrm{AC}$} & $-\mathrm{C}(2008 / 2$ & n.s & 0,199408 & n.s. & 0,125377 & n.s. & -.s.5377/ & n.s. & 0,131436 & n.s. & 0,147948 & n.s. & 0,143171 & n.s. \\
\hline & $(0,6037)$ & & $(0,6956)$ & & $(0,8303)$ & & $(0,2908)$ & & $(0,7071)$ & & $(0,4554)$ & & $(0,4701)$ & \\
\hline \multirow{2}{*}{$\mathrm{AL}$} & $-\mathrm{L}, 4701) / 2$ & n.s. & -.s.701)/ & n.s. & 0,962180 & $*$ & 0,352679 & n.s. & -.s. $2679 / 2$ & n.s. & 0,139783 & n.s. & 0,123474 & n.s. \\
\hline & $(0,5045)$ & & $(0,5711)$ & & $(0,0995)$ & & $(0,3664)$ & & $(0,7814)$ & & $(0,4783)$ & & $(0,5311)$ & \\
\hline \multirow{2}{*}{$\mathrm{AM}$} & $-\mathrm{M}, 5311)) 2$ & n.s. & -.s.311)) & n.s. & 0,106184 & n.s. & -.s.6184 & $* * *$ & $-* * .6184)$ & n.s. & 0,336754 & $*$ & 0,362214 & $* *$ \\
\hline & $(0,5822)$ & & 0,1185 & & $(0,8395)$ & & $(1,43 \mathrm{e}-07)$ & & 0,9690 & & $(0,0592)$ & & $(0,0426)$ & \\
\hline \multirow{2}{*}{$\mathrm{AP}$} & $-\mathrm{P}, 0426) 7)$ & n.s. & -.s.426)7 & n.s. & -.s.426)7 & n.s. & -.s.426)7 & n.s. & -.s.426)7 & n.s. & -.s.426)7) & n.s. & 0,343951 & $*$ \\
\hline & $(0,7844)$ & & $(0,6909)$ & & $(0,7005)$ & & $(0,3012)$ & & $(0,7102)$ & & $(0,7883)$ & & $(0,0808)$ & \\
\hline \multirow{2}{*}{ BA } & $-\mathrm{A}, 0808))$ & $* * *$ & $-* * 0808))$ & n.s. & 0,0870057 & n.s. & -.s.70057 & $*$ & 0,141093 & n.s. & 0,469864 & $* * *$ & 0,955366 & $* * *$ \\
\hline & $(0,0081)$ & & $(0,2736)$ & & $(0,8699)$ & & $(0,0771)$ & & $(0,6570)$ & & $(0,0097)$ & & $(3,25 \mathrm{e}-07)$ & \\
\hline \multirow{2}{*}{$\mathrm{CE}$} & $-\mathrm{E}, 25 \mathrm{e}-07$ & n.s. & $-. s .5 \mathrm{e}-0$ & $* *$ & $-*$ s. $5 \mathrm{e}-07$ & n.s. & -.s.5e-07 & n.s. & -.s.5e-07 & n.s. & -.s.5e-07 & n.s. & 1,11348 & $* * *$ \\
\hline & $(0,1174)$ & & $(0,0206)$ & & $(0,2269)$ & & $(0,3676)$ & & $(0,3841)$ & & $(0,4873)$ & & $(5,74 \mathrm{e}-010)$ & \\
\hline \multirow{2}{*}{$\mathrm{DF}$} & $-\mathrm{F}, 74 \mathrm{e}-01$ & $* *$ & 0,0648184 & n.s. & 0,433165 & n.s. & 0,284747 & n.s. & 0,340161 & n.s. & 0,410956 & $* *$ & 0,479313 & $* *$ \\
\hline & $(0,0424)$ & & $(0,8971)$ & & $(0,4520)$ & & $(0,4608)$ & & $(0,3237)$ & & $(0,0362)$ & & $(0,0148)$ & \\
\hline \multirow{2}{*}{ ES } & $-\mathrm{S}, 0148))$ & n.s & 0,0410082 & n.s & 0,311329 & n.s & -.s11329 & $* * *$ & 0,151894 & n.s & 0,387362 & $* *$ & 0,385639 & $* *$ \\
\hline & $(0,2262)$ & & $(0,9327)$ & & $(0,5766)$ & & $(0,0017)$ & & $(0,6487)$ & & $(0,0414)$ & & $(0,0423)$ & \\
\hline \multirow{2}{*}{ GO } & $-\mathrm{O}, 0423) 20$ & n.s & $-. s 0423) 2$ & n.s & $-. s 0423) 20$ & n.s & $-. s 0423) 2$ & n.s & $-. s 0423) 2$ & n.s & $-. s 0423) 20$ & n.s & 0,604345 & **** \\
\hline & $(0,4827)$ & & $(0,2242)$ & & $(0,9854)$ & & $(0,2250)$ & & $(0,3849)$ & & $(0,9048)$ & & $(0,0017)$ & \\
\hline \multirow{2}{*}{ MA } & $-\mathrm{A}, 0017)) 0$ & n.s & -.s0017)) & n.s & 0,100730 & n.s & $-. s 00730)$ & n.s & -.s00730) & n.s & 0,195802 & n.s & 0,256667 & n.s \\
\hline & $(0,5576)$ & & $(0,5703)$ & & $(0,8624)$ & & $(0,5317)$ & & $(0,3872)$ & & $(0,3205)$ & & $(0,1933)$ & \\
\hline \multirow{2}{*}{ MG } & $-\mathrm{G}, 1933))$ & n.s & -.s1933)) & $*$ & -.s1933)) & n.s & -.s1933) & $* * *$ & $-* * 1933)) 0$ & n.s & 0,298984 & n.s & 0,633668 & $* * *$ \\
\hline & $(0,2500)$ & & $(0,0797)$ & & $(0,7987)$ & & $(0,0003)$ & & $(0,8022)$ & & $(0,1001)$ & & $(0,0006)$ & \\
\hline \multirow{2}{*}{ MS } & $-\mathrm{S}, 0006)) 0$ & n.s & 0,283323 & n.s & 0,441371 & n.s & -.s41371) & * & 0,0386568 & n.s & 0,00552199 & n.s & 0,252063 & n.s \\
\hline & $(0,7121)$ & & $(0,5736)$ & & $(0,4452)$ & & $(0,0584)$ & & $(0,9109)$ & & $(0,9775)$ & & $(0,1987)$ & \\
\hline \multirow{2}{*}{ MT } & 0,0642740 & n.s & $\begin{array}{c}-. s 642740 \\
9\end{array}$ & n.s & -.s6427409 & n.s & -.s642740 & $* *$ & -*s642740 & n.s & -.s642740 & n.s & 0,0557517 & n.s \\
\hline & $(0,5631)$ & & $(0,8670)$ & & $(0,9861)$ & & $(0,0461)$ & & $(0,6266)$ & & $(0,4089)$ & & $(0,7769)$ & \\
\hline \multirow{2}{*}{ PA } & $-A, 7769))$ & n.s & -.s7769)) & n.s & 0,0404491 & n.s & -.s40449 & $* * *$ & $-* * 404491$ & n.s & 0,286452 & n.s & 0,673401 & $* * *$ \\
\hline & $(0,2503)$ & & $(0,5840)$ & & $(0,9383)$ & & $(6,08 \mathrm{e}-06)$ & & $(0,2998)$ & & $(0,1070)$ & & $(0,0002)$ & \\
\hline \multirow{2}{*}{$\mathrm{PB}$} & $-B, 0002) 6$ & n.s & $-. s 0002) 6$ & n.s & $-. s 0002) 6)$ & n.s & 0,0304153 & n.s & -.s304153 & n.s & -.s304153)) & n.s & 0,644274 & $* * *$ \\
\hline & $(0,2975)$ & & $(0,2344)$ & & $(0,9083)$ & & $(0,9359)$ & & $(0,6319)$ & & $(0,9713)$ & & $(0,0009)$ & \\
\hline PE & $-\mathrm{E}, 0009))$ & $* *$ & $-*, 0009))$ & n.s & 0,0746847 & n.s & 0,622882 & $*$ &,- 6228827 & n.s & 0,146121 & n.s & 0,925594 & $* * *$ \\
\hline
\end{tabular}


Igor Santos Tupy, Marco Crocco, Fernanda Faria Silva

\begin{tabular}{|c|c|c|c|c|c|c|c|c|c|c|c|c|c|c|}
\hline & $(0,0264)$ & & $(0,3212)$ & & $(0,8904)$ & & $(0,0880)$ & & $(0,5965)$ & & $(0,4266)$ & & $(1,15 \mathrm{e}-06)$ & \\
\hline \multirow{2}{*}{ PI } & $-\mathrm{I}, 15 \mathrm{e}-06$ & n.s & $-. s 15 \mathrm{e}-06$ & n.s & 0,334303 & n.s & 0,453291 & n.s & 0,00894481 & n.s & -.s0894481) & n.s & 0,725927 & $* * *$ \\
\hline & $(0,1177)$ & & $(0,5314)$ & & $(0,5511)$ & & $(0,2287)$ & & $(0,9787)$ & & $(0,9695)$ & & $(0,0002)$ & \\
\hline \multirow{2}{*}{ PR } & $-\mathrm{R}, 0002)) 1$ & n.s & 0,0380334 & n.s & 0,307435 & n.s & -.s074354 & $*$ & -.s074354 & n.s & 0,0839177 & n.s & 0,528351 & $* * *$ \\
\hline & $(0,4314)$ & & $(0,9383)$ & & $(0,5858)$ & & $(0,0674)$ & & $(0,1985)$ & & $(0,6605)$ & & $(0,0062)$ & \\
\hline \multirow{2}{*}{$\mathrm{RJ}$} & $-\mathrm{J}, 0062))$ & * & $-\mathrm{J}, 0062))$ & $*$ & 0,157473 & n.s & 0,0184660 & n.s & -.s184660 & n.s & 0,154063 & n.s & 0,945390 & $* * *$ \\
\hline & $(0,0573)$ & & $(0,0841)$ & & $(0,7680)$ & & $(0,9589)$ & & $(0,1981)$ & & $(0,3947)$ & & $(4,81 \mathrm{e}-07)$ & \\
\hline \multirow{2}{*}{$\mathrm{RN}$} & $-\mathrm{N}, 81 \mathrm{e}-07)$ & n.s & -.s81e-07 & n.s & 0,508521 & n.s & -.s085217 & * & -.s085217 & n.s & 0,228038 & n.s & 0,151550 & n.s \\
\hline & $(0,7970)$ & & $(0,1651)$ & & $(0,3752)$ & & $(0,0830)$ & & $(0,3080)$ & & $(0,2408)$ & & $(0,4351)$ & \\
\hline \multirow{2}{*}{ RO } & $-\mathrm{O}, 4351) 7$ & **** & 0,0522481 & n.s & 0,536891 & n.s & 0,726031 & $* *$ & $-* 7260311)$ & n.s & 0,282058 & n.s & 1,22269 & $* * *$ \\
\hline & $(0,0004)$ & & $(0,9076)$ & & $(0,2993)$ & & $(0,0372)$ & & $(0,9418)$ & & $(0,1082)$ & & $(5,73 e-01)$ & \\
\hline \multirow{2}{*}{ RR } & $-\mathrm{R}, 73 \mathrm{e}-01$ & n.s & 0,0439642 & n.s & 0,206555 & n.s & -.s065552 & n.s &.$- s 065552$ & n.s & 0,207061 & n.s & 0,517483 & **** \\
\hline & $(0,2180)$ & & $(0,9299)$ & & $(0,7187)$ & & $(0,4779)$ & & $(0,5452)$ & & $(0,2870)$ & & $(0,0083)$ & \\
\hline \multirow{2}{*}{ RS } & $-\mathrm{S} 0,0083))$ & n.s & $-. s, 0083)$ & n.s & $-. s, 0083)$ & n.s & -.s,0083 & **** & $-* *, 0083)$ & n.s & -.s,0083)) & n.s & 0,695365 & **** \\
\hline & $(0,6482)$ & & $(0,3988)$ & & $(0,1093)$ & & $(0,0055)$ & & $(0,2821)$ & & $(0,6510)$ & & $(0,0002)$ & \\
\hline \multirow{2}{*}{ SC } & $-\mathrm{C}, 0002)))$ & n.s & 0,0385788 & n.s & -.s385788 & n.s & -.s385788 & $* *$ & -*s385788 & n.s & 0,0975651 & n.s & 0,466820 & $* *$ \\
\hline & $(0,5472)$ & & $(0,9376)$ & & $(0,7388)$ & & $(0,0253)$ & & $(0,3205)$ & & $(0,6105)$ & & $(0,0156)$ & \\
\hline \multirow{2}{*}{ SE } & $-\mathrm{E}, 0156) 1$ & $* *$ & $-*, 0156) 1$ & n.s & 0,393828 & n.s & 0,286055 & n.s & 0,0927407 & n.s & 0,0706079 & n.s & 0,861935 & $* * *$ \\
\hline & $(0,0482)$ & & $(0,4003)$ & & $(0,4755)$ & & $(0,4396)$ & & $(0,7786)$ & & $(0,7055)$ & & $(7,54 \mathrm{e}-06)$ & \\
\hline \multirow{2}{*}{ SP } & $-P, 54 \mathrm{e}-06)$ & n.s & $-. s 54 \mathrm{e}-06$ & n.s & $-. s 54 \mathrm{e}-06$ & n.s & $-. s 54 \mathrm{e}-0$ & $* * *$ & $-* * 54 \mathrm{e}-06$ & n.s & 0,0853314 & n.s & 0,424249 & $* *$ \\
\hline & $(0,8050)$ & & $(0,3539)$ & & $(0,6714)$ & & $(0,0058)$ & & $(0,1474)$ & & $(0,6522)$ & & $(0,0261)$ & \\
\hline \multirow{2}{*}{ TO } & $-\mathrm{O}, 0261) 4)$ & n.s & -.s0261)4 & n.s & 0,197245 & n.s & -.s972454 & $* *$ & 0,0174597 & n.s & 0,172275 & n.s & 0,362498 & * \\
\hline & $(0,5153)$ & & $(0,4259)$ & & $(0,7289)$ & & $(0,0160)$ & & $(0,9591)$ & & $(0,172275)$ & & $(0,0613)$ & \\
\hline
\end{tabular}

$(* * *)$ Significante a $1 \%$. (**) Significante a 5\%. (*) Significante a 10\%. (n.s.) Não Significante. P-valores entre parênteses.

Fonte: Elaboração própria por meio do Software GRETL. 